into three chapters. The first chapter deals with certification and how to become certified before March 31st, 1905, and after that date. The second chapter gives the rules and regulations issued by the Central Midwives Board which the certified midwife will be required to obey. The final chapter deals with her relations and duties, as a certified midwife, to the local authority of the area in which she intends to practise as a midwife. There is an appendix of the names of approved institutions under Section $\mathrm{C}$ of the rules of the Central Midwives Board and of institutions the certificates of which are accepted as qualifications under Section 2 of the Act.

\section{JOURNALS AND MAGAZINES.}

Medical Electrology and Radiology.-Three articles published in the June number are continued in July-namely, those on the Treatment of Affections of the Gastro-intestinal Tract, by Dr. George Herschell ; on the Application of Highfrequency Currents, by Mr. C. A. Wright; and the Lectures on Physics applied to Medicine, by Sir Oliver Lodge. The meetings of the British Electrotherapeutic Society are reported at considerable length as usual. The July number also contains articles on the $\mathrm{X}$ Rays in the Diagnosis of Joint Conditions and on Treatment by Blue Light.

Caledonian Medical Joumal.-The opening article in the July number is a Plea for More Accurate Clinical Observation by Dr. James Mackenzie of Burnley, the author of an excellent work on the study of the pulse by means of various recording instruments such as the sphygmograph. Other contributions are on the Medicinal Plants found in the Scottish Highlands, by Mr. Henry White; on Heredity in the Scottish Highlands, by Mr. A. Macdonald; and on the Use of Alcoholic Beverages in Scotland about the Year 1735-namely, before the consumption of whisky became generalised.

Journal of the Irish Medical Association.--The July number is mainly occupied with a report of the annual general meeting of the Association held in the buildings of the Royal College of Surgeons in Dublin on June 7th. The leading article is on the subject of Superannuation for Poorlaw Medical Officers.

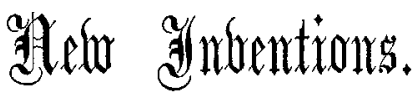

\section{A HANDY AID TO CLEANLY MIDWIFERY.}

BELIEVING that any appliance which will make surgical asepsis, and consequently safety, easier of attainment in operative midwifery will be welcomed by the profession at large, especially if it does not entail carrying cumbersome apparatus, I append a description of a combined steriliser and irrigator which $I$ have invented and have found very useful in my own practice. It is not heavy and not bulky, the measurements being $16 \times 3 \frac{1}{2} \times 2 \frac{1}{2}$ inches. It will therefore go quite easily into any ordinary midwifery bag and the forceps, douche tube, \&c., can be packed inside it to save space. It consists of a kind of box, made of sheet copper, tinned inside, and having an opening at one end for five inches of its length, which I have found sufficient for the insertion and removal of any midwifery instrument. Near the other end is a hole, tapped to receive a screwed-in nozzle to which to attach rubber tubing. It is fitted with three supports which fold quite flat when not in use. Nos. 1 and 2 of these form the legs when the instrument is in the horizontal position in use as a steriliser, while Nos. 2 and 3 form a firm base of support when the instrument is in a vertical position in use as an irrigator.
No. 1 can in this position be used as a hamdle or as a suspending loop.

My manner of using the instrument is as follows. $100 \mathrm{n}$ ascertaining that the application of forceps is likely to be necessary I put my forceps (Anderson's or the BarnesSimpson pattern with metal handles), together with a Bozemann's douche-tube, into the steriliser, pour on boiling water from a kettle, and light the lamp. If the instruments are wanted immediately I usually put a clove hitch of thread on the ends of the handles to facilitate removal, but they

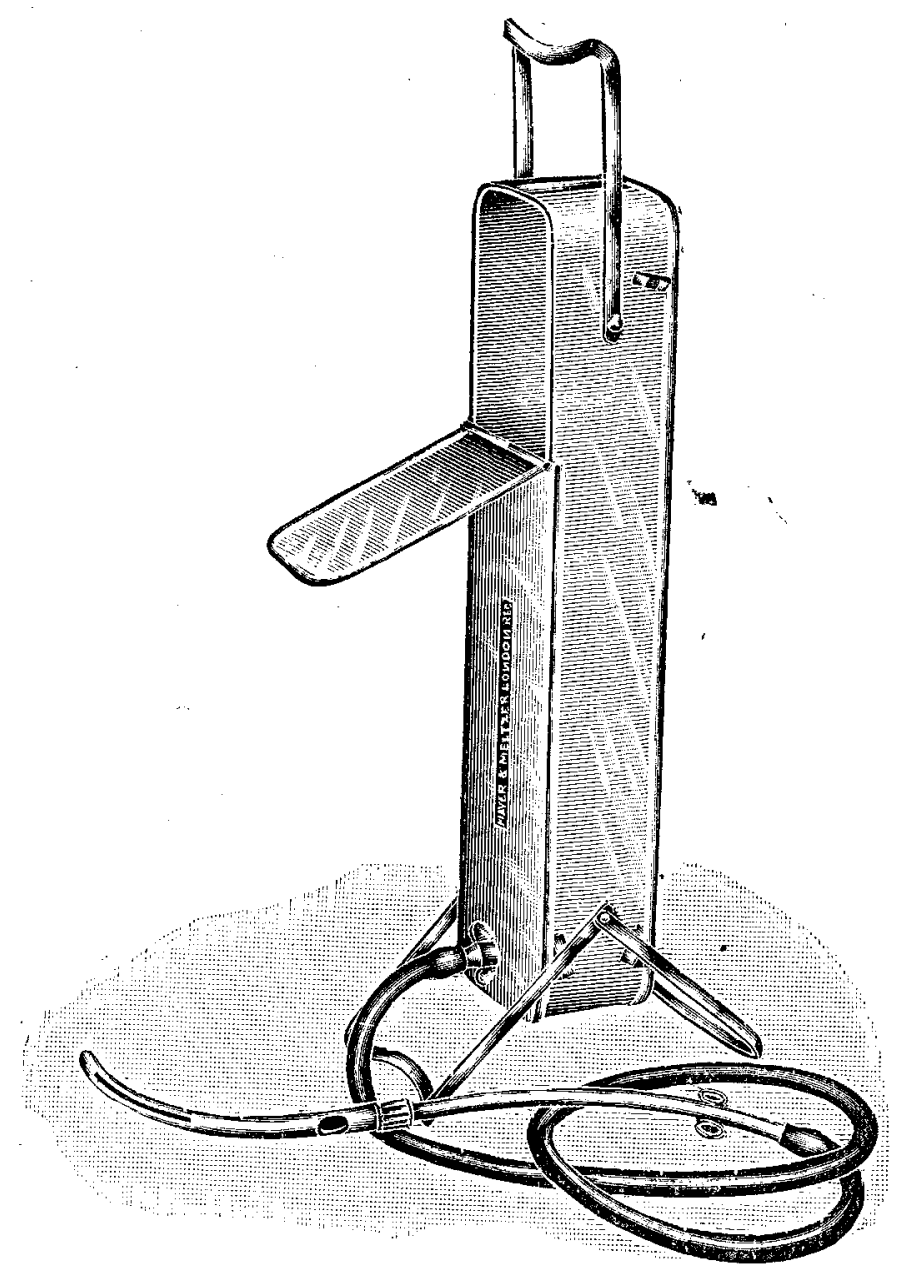

can be removed by hand a very short time after boiling if the can be placed vertically first. Having removed them and allowed them to cool in the air till they are cool enough to use I lubricate with biniodide of mercury soap and apply them. By the time the third stage is over the water in the can is probably cool enough to use for douching; if not, as ascertained by thermometer, as cold boiled water is not usually available I have added some of the antiseptio (generally potassio-mercuric iodide) to some cold water while the instruments were boiling, so that by now the solution is quite aseptic and will produce when mixed with the hot water a solution of about the right strength. This having been added to the hot water so as to produce a mixture of the required temperature, the tube is connected up and the irrigation proceeded with. I know that there is much diversity of opinion respecting the necessity and even the advisability of douching; but I am speaking now of operative cases, and $I$ use a douche in every case in which $\mathrm{my}$ hand or any instrument has been introduced into the uterus. I do not advise the abandonment of our old friend the "Higginson," as it is useful for the preliminary vaginal douche and also sometimes for rectal purposes.

The combined steriliser and irrigator has been very neatly made for me in polished copper, tinned inside, by Messrs. Mayer and Meltzer of 71, Great Portland-street, who have carried out my ideas very faithfully and with strict regard to both utility and portability, and to them I am indebted for an improvement upon my original design in the matter of attaching the supports. The steriliser as made is, of course, available for the general purposes of a steriliser as well as for its special use in midwifery cases. Its fluid capacity when standing vertically for use as an irrigator is about four pints.

WM. Salisbury-Sharpe, M.D. Durh., M.R.C.S. Eng., Cleveland-terrace, W. $\quad$ L.R.C.P. Lond., D.P.H. 